\title{
Levels of vitamin D receptor and CYP24A1 in patients with end-stage renal disease.
}

\author{
Jia-Jun Ye ${ }^{1}$, Tian-Biao Zhou ${ }^{2}$, Yun-Fang Zhang ${ }^{1}$, Qi Wang ${ }^{1}$, Yan-Yan Su', \\ Jia-Min Tang ${ }^{1}$, Hong-Yan Li ${ }^{1}$
}

1. Department of Nephrology, Huadu District People's Hospital, Southern Medical University, Guangzhou 510800, China

2. Department of Nephrology, the Sixth Affiliated Hospital, Sun Yat-Sen University, Guangzhou 510655, China

\begin{abstract}
:
Objective: This study was performed to detect the expression of vitamin D receptor (VDR) and cytochrome P450, family 24, subfamily A, polypeptide 1 (CYP24A1) in 24 end stage renal disease (ESRD) patients and 24 healthy controls.

Method: In this study, 24 ESRD patients and 24 healthy controls were included.

Results: In our study, the levels of VDR in patients with ESRD were reduced when compared with those from healthy controls $(5.20 \pm 0.32$ vs $8.59 \pm 1.03 ; \mathrm{P}<0.01)$. However, the levels of CYP24A1 in ESRD patients were increased than those from healthy controls $(50.18 \pm 21$ vs $7.78 \pm 1.31 ; \mathrm{P}<0.01)$. Correlation analysis showed that VDR levels were negatively correlated with CYP24A1 ( $\mathrm{r}=-0.723 ; \mathrm{P}<0.01)$.

Conclusion: VDR levels were reduced and CYP24A1 levels were increased in patients with ESRD, and VDR levels were negatively correlated with CYP24A1.

Keywords: Vitamin D receptor (VDR), CYP24A1, end-stage renal disease (ESRD)

DOI: http://dx.doi.org/10.4314/ahs.v16i2.14

Cite as: Ye J-J, Zhou T-B, Zhang Y-F, Wang Q, Su Y-Y, Tang J-M, et al. Levels of vitamin D receptor and CYP24A1 in patients with end-stage renal disease. Afri Health Sci 2016;16(2): 462-467. http:/ / dx.doi.org/10.4314/ abs.v16i2.14
\end{abstract}

\section{Introduction}

End stage renal disease (ESRD) represents a clinical condition in which there has been an irreversible loss of endogenous renal function. ESRD is an increasing problem worldwide and is a major health problem associated with very high morbidity and mortality ${ }^{1,2}$. Patients with ESRD must receive a kidney transplant or live on dialysis ${ }^{1,3}$. Reduction in serum 1,25 (OH) (2)D level plays an important role in the pathophysiology of altered bone and mineral metabolism among patients with advanced stages of chronic kidney disease (CKD). Alterations in vitamin D

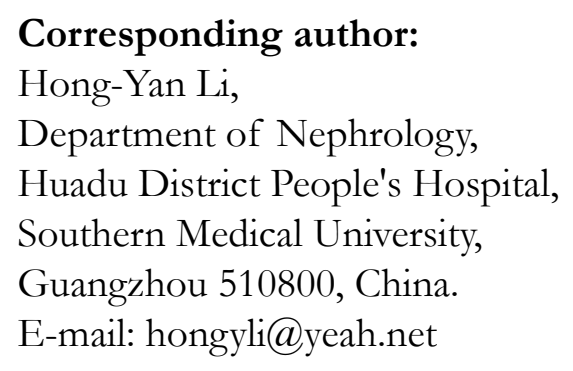

metabolism are included. Many adverse events have been associated with vitamin $\mathrm{D}$ deficiency or lack of vitamin $\mathrm{D}$ receptor (VDR) activation both in the general population and CKD patients ${ }^{4}$.

Vitamin D regulates the action of hormone responsive genes, is involved in cell cycle regulation, differentiation and apoptosis, and plays a role involving the renal diseases acting through the vitamin $\mathrm{D}$ receptor $(\mathrm{VDR})^{5}$. The VDR is a nuclear hormone receptor mediating the activity of vitamin D hormone ${ }^{6}$. The major role of cytochrome P450, family 24, subfamily A, polypeptide 1 (CYP24A1) is to maintain 1,25-dihydroxyvitamin D3 (1,25(OH)2D3) homeostasis ${ }^{7}$. In this study, we investigated the levels of VDR and CYP24A1, and the relationship between them in ESRD patients.

\section{Materials and methods Object of study and specimen collection}

All patients we enrolled had been diagnosed with ESRD at the Department of Nephrology, Huadu District Peo- 
ple's Hospital, Southern Medical University, Guangzhou, China, between March 2014 and October 2014. Relevant specimens were taken from 24 ESRD patients with maintenance hemodialysis. There were 13 males and $11 \mathrm{fe}-$ males and the age was $46.88 \pm 15.53$ years old.

Furthermore, the control group recruited 24 healthy volunteers without any renal disease. There were 13 males and 11 females and the age was $44.08 \pm 14.27$ years old. There were no statistically significant differences among the above two groups in gender and age $(\mathrm{P}=0.321$ and $\mathrm{P}=1$ respectively; Table 1$)$. The study was approved by the Ethics Committee of our Medical Faculty and written informed consents were obtained from all patients and the healthy controls before study entry.

\section{Specimen collection and procession}

$3 \mathrm{ml}$ blood sample was drawn from each ESRD patients and healthy controls, and the blood sample was placed into a dry and clean tube. Then put it aside at room temperature for 30 minutes until it clotted. After the sample was centrifugated at $3000 \mathrm{r} / \mathrm{min}$ at room temperature for 5 minutes, $2 \mathrm{ml}$ serum was extracted and shifted into another dry and clean tube. The sample was stored in $-20^{\circ} \mathrm{C}$ refrigerator for inspection.

\section{Detection serum VDR, CYP24A1 levels by ELISA.}

Operations were performed strictly in accordance with the instruction of VDR, CYP24A1 ELISA kit (Cusabio, Inc., China). Detection steps as follows: all the specimens were removed from $-20^{\circ} \mathrm{C}$ refrigerator and balanced to room temperature. $10000 \mathrm{pg} / \mathrm{m} 1$ standard solution was prepared, and followed by serial dilution with sample diluent solution and became 400, 200, 100, 50, 25, 12.5, 6.25 and $0 \mathrm{pg} / \mathrm{ml}$ for VDR and 500, 250, 125, 62.5, 31.5, 15.6 and $0 \mathrm{pg} / \mathrm{ml}$ for CYP24A1, respectively. The sample diluent solution was taken as the standard of $0 \mathrm{pg} / \mathrm{ml}$, and $100 \mu \mathrm{l}$ different concentration of the above-mentioned solutions were taken to fill the first row ( $\mathrm{Al}-\mathrm{Hl}$ ) in the ELISA plate in accordance with the sequence of concentration. Other empty wells were filled with $100 \mu$ l diluent of serum or urine sample which was diluted by 1:10. After the incubation in $37^{\circ} \mathrm{C}$ incubator for $90 \mathrm{~min}-$ utes, we poured away the liquid and filled the holes with $100 \mu$ l biotinylated anti-human antibody of VDR, CY$\mathrm{P} 24 \mathrm{~A} 1$, covered the plate and put into $37^{\circ} \mathrm{C}$ incubator for 60 minutes. After the incubation, the plate was washed with phosphate-buffered saline (PBS) three times and $100 \mu l$ streptavidin labeled horseradish peroxidase (HRP) was added into each hole; the plate was covered and put into $37^{\circ} \mathrm{C}$ incubator again for 30 minutes. After washing the plate with PBS solution three times and adding $90 \mu \mathrm{l}$ color reagent, we put the plate into the incubator for 30 minutes repeatedly. Finally, $100 \mu l$ stopping solution was added into each well to terminate the reaction. The absorbance of the samples was detected at $450 \mathrm{~nm}$ by enzyme-labeling measuring instrument (Bio-Tek Co., USA) and standard curve was scaled to calculate the VDR, CYP24A1 levels of serum specimens.

\section{Statistical analysis}

Database by Excel 2003 was established to include all the data in our study; statistical description and hypothesis test were analyzed by statistical package for the social science 13.0 (SPSS 13.0). Statistical description of the measurement materials were expressed as mean plus or minus standard deviation (mean $\pm \mathrm{SD}$ ). The $\mathrm{t}$ test with different samples was adopted for comparison between groups. Pearson correlation coefficient was used to determine the relationships between VDR and CYP24A1.P $<0.05$ was chosen as the level of statistical significance.

\section{Results}

\section{Serum VDR levels in two groups}

Compared with the control group's, levels of serum VDR in ESRD group were significantly lower $(5.20 \pm 0.32 \mathrm{pg} /$ $\mathrm{ml}$ vs. $46.25 \pm 12.87 \mathrm{pg} / \mathrm{m} 1, \mathrm{P}<0.01$; Table 1 and Figure 1). 
Table 1. The characteristics and the VDR, CYP24A1 expression in two groups

\begin{tabular}{llll}
\hline & ESRD $(\mathrm{n}=24)$ & Control $(\mathrm{n}=24)$ & $\mathrm{P}$ \\
\hline Age & $46.88 \pm 15.53$ & $44.08 \pm 14.27$ & 0.321 \\
Sex $(\mathrm{man} /$ female $)$ & $13(54.17 \%) / 11(45.83 \%)$ & $13(54.17 \%) / 11(45.83 \%)$ & 1.000 \\
VDR & $5.20 \pm 0.32$ & $8.59 \pm 1.03$ & $<0.01$ \\
CYP24A1 & $50.18 \pm 21$ & $7.78 \pm 1.31$ & $<0.01$ \\
\hline
\end{tabular}

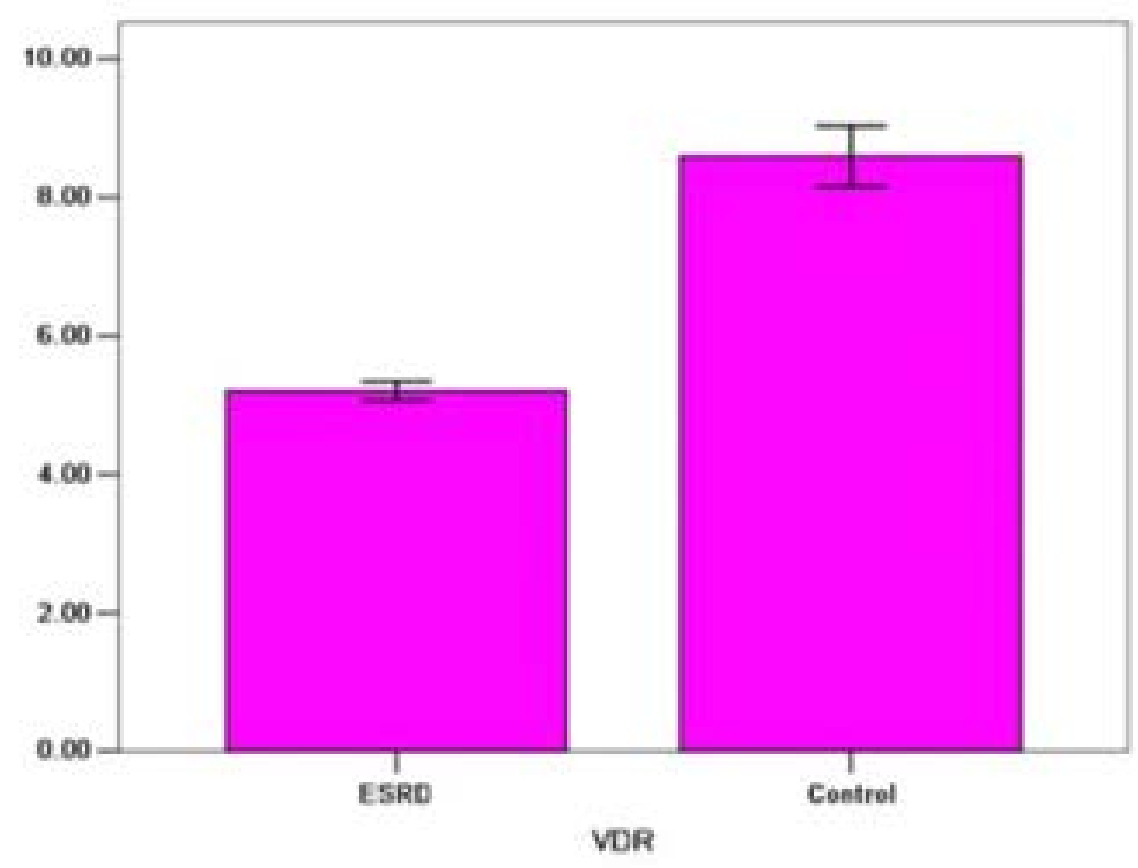

Figure 1 VDR levels in two groups. ": when compared with ESRD group, $P<0.01$

Serum CYP24A1 levels in two groups

In ESRD group, the levels of serum CYP24A1 were markedly higher than those in control group $(50.18 \pm 21$ $\mathrm{pg} / \mathrm{ml}$ vs. $7.78 \pm 1.31 \mathrm{pg} / \mathrm{ml}, \mathrm{P}<0.01$; Table 1 and Figure 2). 


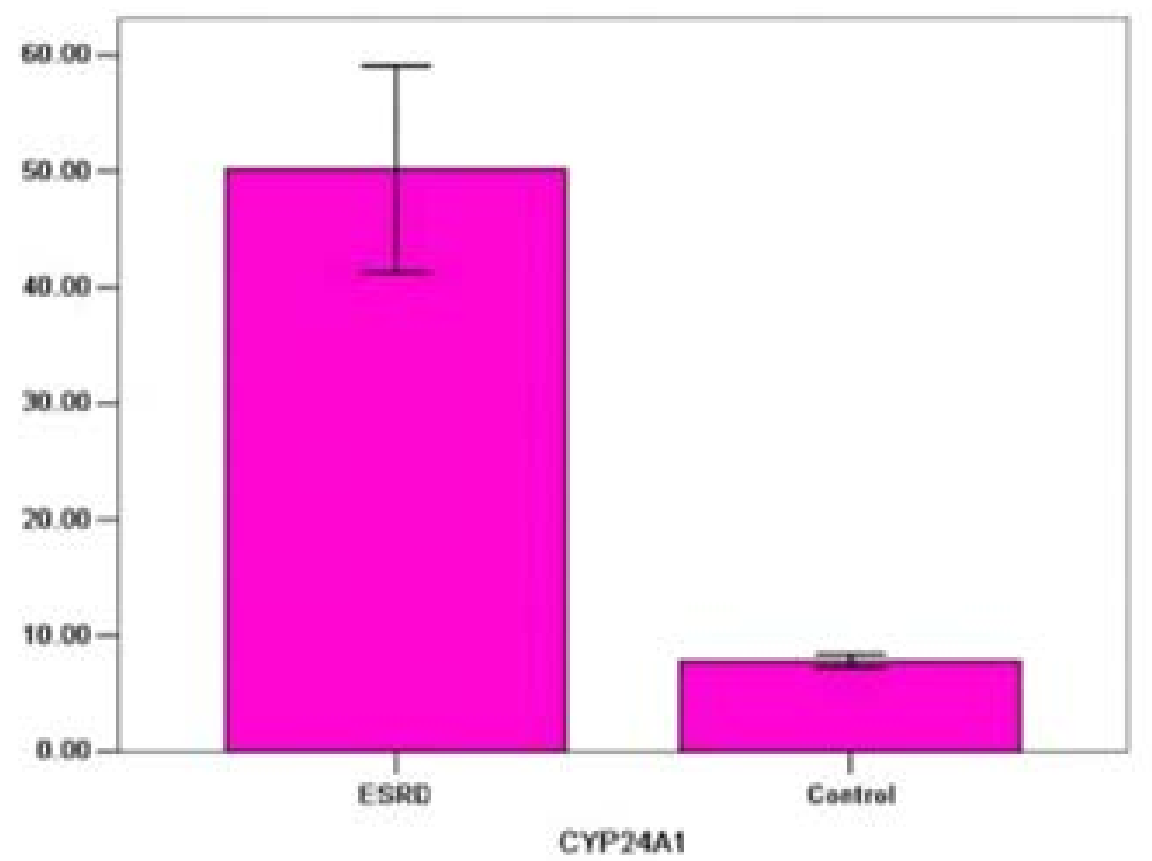

Figure 2 CYP24A1 levels in two groups. * : when compared with ESRD group, $\mathrm{P}<\mathbf{0 . 0 1}$

\section{Correlation analysis}

Significant negative correlation was noted between VDR and CYP24A1 ( $\mathrm{r}=-0.664, \mathrm{P}<0.05)$.

\section{Discussion}

End stage renal disease (ESRD) is a major health problem associated with very high morbidity and mortality. Hemodialysis is one of the most important treatment measure of renal replacement therapy for ESRD patients. However, chronic kidney disease-mineral and bone disorders (CKD-MBD) ranks among clinically and pathogenetically significant complications in patients with CKD, and CKD-MBD is associated with vascular calcification and abnormal electrolytes that lead to cardiovascular disease and mortality ${ }^{8-10}$. In this study, we detected the association of VDR with CYP24A1, and their expressions in ESRD patients.

In our study, we found that the VDR levels in ESRD patients were reduced and the CYP24A1 levels were increased in ESRD patients. In previous, vitamin D deficiency was regarded as one of the most important characteristics for the patients with ESRD. VDR activators can improve the CKD-MBD and vascular calcification.
However, the VDR level in ESRD patients in serum was rarely studied. In previous, Denda et $\mathrm{al}^{11}$ conducted a study in rats and found that account for the decrease in VDR content in parathyroid glands of uremic rats and that treatment with 1,25-D3 or OCT prevents this decrease ameliorating the development of secondary hyperparathyroidism. Fukuda et $\mathrm{al}^{12}$ investigated VDR distribution in surgically-excised parathyroids obtained from chronic dialysis patients by immunohistochemistry, and found that the decreased VDR density in parathyroids might contribute to the progression of secondary hyperparathyroidism and to the proliferation of parathyroid cells that was seen in uremia.There were lots of studies focusing on the VDR gene polymorphisms with susceptibility to CKD or ESRD ${ }^{13-18}$. In this study, we reported that VDR was low expression in the serum of ESRD patients. However, more studies should be performed to confirm it.

Furthermore, we also investigated the expression of CYP24A1 in ESRD patients. There was also few study focusing on it in ESRD patients. Amplified CYP24 expression was demonstrated in uremic rats, and it suggested that CYP24 had an etiological role in vitamin D insufficiency commonly associated with $\mathrm{CKD}^{19}$. There was rarely 
any study investigating its expression in ESRD patients. Our study reported that expression of CYP24A1 was increased in ESRD patients. However, the sample size was small, and more studies should be performed.

Interestingly, we also found that VDR was negatively correlated with CYP24A1 in ESRD patients. There was also scarce reports to study this investigation in ESRD patients. However, the detailed mechanism should be studied in the further.

To sum up those mentioned above, we drew the conclusion that VDR levels were reduced and CYP24A1 levels were increased in patients with ESRD, and VDR levels were negatively correlated with CYP24A1 levels. However, the sample size in our study was small and the subgroup analysis of ESRD patients should be performed in future.

\section{Acknowledgements}

This study was supported by the Guangzhou Medical Key Subject Construction Project (2013-2015).

\section{Conflict of interest}

The authors declare that they have no conflict of interest.

\section{References}

1. Zhou TB, Yin SS, Qin YH. Association between angiotensin-converting enzyme insertion/deletion gene polymorphism and end-stage renal disease susceptibility. J Renin Angiotensin Aldosterone Syst. 2014;15(1):22-31.

2. Zhou TB, Yin SS, Qin YH. Association of angiotensinogen M235T gene polymorphism with end-stage renal disease risk: a meta-analysis. Mol Biol Rep. 2013;40(2):765 $-72$.

3. Zhang YF, Zhou TB, Jiang ZP, Li HY. Association of vitamin D receptor BsmI (rs1544410) gene polymorphism with the intact parathyroid hormone (iPTH) level among patients with end-stage renal disease. J Recept Signal Transduct Res. 2015;35(2):133-6.

4. Bover J, Lloret MJ, DaSilva I, Furlano M, Diaz M, Herreros A, et al. Role of vitamin D receptor activators in peritoneal dialysis. Contrib Nephrol. 2012;178:124-42 .

5. Pulito C, Terrenato I, Di Benedetto A, Korita E, Goeman F, Sacconi A, et al. Cdx2 polymorphism affects the activities of vitamin D receptor in human breast cancer cell lines and human breast carcinomas. PLoS One. 2015;10(4): e0124894.

6. Golan MA, Liu W, Shi Y, Chen L, Wang J, Liu T, et al. Transgenic Expression of Vitamin D Receptor in Gut Epithelial Cells Ameliorates Spontaneous Colitis Caused by Interleukin-10 Deficiency. Dig Dis Sci. 2015.

7. Brozyna AA, Jochymski C, Janjetovic Z, Jozwicki W, Tuckey RC, Slominski AT. CYP24A1 expression inversely correlates with melanoma progression: clinic-pathological studies. Int J Mol Sci. 2014;15(10):19000-17.

8. Miura S, Yoshihisa A, Takiguchi M, Shimizu T, Nakamura Y, Yamauchi H, et al. Association of hypocalcemia with mortality in hospitalized patients with heart failure and chronic kidney disease. J Card Fail. 2015.

9. Zamboch K, Krejci K, Skarda J, Tichy M, Uberall I, Skypalova $\mathrm{P}$, et al. Histomorphometric diagnostics of renal osteopathy in chronic dialysis patients at high risk of cardiovascular disease. Int Urol Nephrol. 2015.

10. Dusilova Sulkova S. Bone disease in chronic renal failure and its modern therapy. Vnitr Lek. 2011; 57(7-8 ):620-5.

11. Denda M, Finch J, Brown AJ, Nishii Y, Kubodera N, Slatopolsky E. 1,25-dihydroxyvitamin D3 and 22-oxacalcitriol prevent the decrease in vitamin $\mathrm{D}$ receptor content in the parathyroid glands of uremic rats. Kidney Int. 1996; 50(1):34 -9.

12. Fukuda N, Tanaka H, Tominaga Y, Fukagawa M, Kurokawa K, Seino Y. Decreased 1,25-dihydroxyvitamin D3 receptor density is associated with a more severe form of parathyroid hyperplasia in chronic uremic patients. J Clin Invest. 1993; 92(3):1436 -43.

13. Amato M, Pacini S, Aterini S, Punzi T, Gulisano M, Ruggiero M. Iron indices and vitamin D receptor polymorphisms in hemodialysis patients. Adv Chronic Kidney Dis. 2008; 15(2):186-90.

14. de Souza CM, Braosi AP, Luczyszyn SM, Avila AR, de Brito RB, Jr., Ignacio SA, et al. Association between vitamin $\mathrm{D}$ receptor gene polymorphisms and susceptibility to chronic kidney disease and periodontitis. Blood Purif. 2007; 25(5-6 ):411-9.

15. Pourfarzam M, Nia KM, Atapour A, Sadeghi HM. The influence of BsmI and TaqI vitamin D receptor gene polymorphisms on the intensity of hyperparathyroidism in Iranian hemodialysis patients. Adv Biomed Res. 2014;3:213. 
16. Shishkin AN, Mazurenko SO, Aseev MV. Effect of TT genotype of the vitamin $\mathrm{D}$ receptor gene on bone mineral density in dialysis patients. Ter Arkh. 2010;82(6):39-43. 17. Tripathi G, Sharma R, Sharma RK, Gupta SK, Sankhwar SN, Agrawal S. Vitamin D receptor genetic variants among patients with end-stage renal disease. Ren Fail. 2010;32(8):969-77.
18. Yang L, Wu L, Fan Y, Ma J. Associations among four polymorphisms (BsmI, FokI, TaqI and ApaI) of vitamin $\mathrm{D}$ receptor gene and end-stage renal disease: a meta-analysis. Arch Med Res. 2015; 46(1):1-7.

19. Posner GH, Helvig C, Cuerrier D, Collop D, Kharebov A, Ryder K, et al. Vitamin D analogues targeting CYP24 in chronic kidney disease. I Steroid Biochem Mol Biol. 2010; 121(1-2):13-9. 